\title{
Alternatives for the Internet: A Journey into Decentralised Network Architectures and Information Commons
}

\author{
Mélanie Dulong de Rosnay* and Francesca Musiani**
}

*Centre for Internet and Society, CNRS, Paris, France, melanie.dulong@cnrs.fr, https://cis.cnrs.fr/melanie-dulong/

${ }^{* *}$ Centre for Internet and Society, CNRS, Paris, France, francesca.musiani@cnrs.fr, https://cis.cnrs.fr/francesca-musiani/

\begin{abstract}
For over twenty years, alternative forms of organising and networking - fuelled by the Internet but sometimes pre-dating it - have been discussed as possible responses to the dynamics of concentration, centralisation and capture exemplified in the current pervasively digital world by Internet giants such as Google and Facebook. This article takes stock of the lessons learned by the authors in over a decade of research on decentralised/P2P network architectures and on information commons, to suggest some 'ways forward' for these alternatives for the Internet.
\end{abstract}

Keywords: Internet, alternatives, peer-to-peer, P2P, decentralisation, information commons, digital commons, data commons, urban commons, intellectual property, capitalism, peer production

\section{Introduction}

In a world dominated by Internet giants - such as Google, Facebook, Apple, Amazon and Microsoft, the infamous GAFAM - whose business models feed on the massive collection, retention and elaboration of our data and content, are there any alternatives to capitalism? For at least twenty years, from the beginnings of Napster ${ }^{1}$ in 1999 (Ku 2002), decentralised network architectures, or peer-to-peer (P2P), have been discussed as a possible response to these dynamics of concentration, centralisation and capture (e.g. Schoder and Fischbach 2003). Indeed, the choice by engineers and designers to develop P2P architectures over centralised models has many implications for the design of the online services and media that we use on a daily basis, and for our lives as Internet users (Musiani 2015; Méadel and Musiani 2015).

In parallel, and also for more than two decades, new ways of producing and sharing information based on the commons, or commons-based peer production models (Benkler 2006), have also been emerging online, with the development of information and digital commons (Bollier and Pavlovich 2008; Stalder 2010; Dulong de Rosnay and Le Crosnier 2012). Free and Open Source software (F/OSS, which started as a movement in 1983), Free Culture, Wikipedia, and the open science and open data movements are providing content with more freedoms to users and authors. Information and digital commons have proved a noteworthy alternative to the business models of the entertainment and knowledge economy built on exclusive rights on software, scientific articles, and culture - all produced within the framework of a strong intellectual property system, crucial for commercial production models.

\footnotetext{
${ }^{1}$ https://en.wikipedia.org/wiki/Napster
} 


\section{Maximising the Internet's Value for Society}

Decentralised network architectures and information commons refer to a particular form of organisation: a network of peers, or equals, that allows several individuals to collaborate spontaneously (and, in the case of P2P architectures, without the need for a central coordinating entity: Schollmeier 2001). In such an architecture, the responsibility for exchanges or communications lies at the periphery of the system, and all of its resources are distributed among several machines. P2P architectures can enable the self-organised and decentralised coordination of previously under-utilised or limited resources, or the greater inclusion of users. P2P networks have three main features: each node of the network can act as both a supplier and a consumer of resources (information, bandwidth, storage and computing capacity, etc.); there is no central coordinating authority for the organisation of the network; and there is no entity that has a global vision of it - each node can determine autonomously how it makes its resources available to other nodes.

Indeed, some comparable principles exist in the arrangements that focus on the production of tangible and intangible commons. Commons-based peer production is based on the self-organisation of communities that take shared decisions to organise rights of use, share responsibilities in production, and enforce control or authority in case sanctions are needed; commons-based peer production is a model whose governance rules do not involve the state or the market (Benkler 2006). The commons are also based on decentralised coordination, even if research has shown that some centralised figures stand out and contribute more to particular tasks (O'Neil 2009).

On the basis of these technical and governance principles, philosophers and social scientists have explored the forms of organisation of both P2P and the commons as alternative ways not only to distribute software, files and cultural works among peers, but also to manage the Internet, and to develop alternative applications, platforms, knowledge, or creations. This ensemble of models can potentially form the basis of efficiency, security and "sustainable digital development" (Linkov et al. 2018) for P2P, and of agile sharing, open access and collaborative work within the digital commons.

Globally, at the level of individual and collective rights, both decentralised architectures and information commons intend to maximise the value of the Internet for society, to perform the common good (see Fuchs 2020 on the ethics of digital commons), and to offer more rights and freedom to users, based on democratic, privacy and access to knowledge principles. The idea of a better value for society grounded in decentralised arrangements is explored, in particular, by the philosopher Michel Bauwens, who advocates that P2P should be the foundation of a "general theory" of peer production for collaborative and direct human interaction - an emerging, pervasive and social phenomenon that may profoundly influence the ways in which society and human civilization itself is organised, and that intersects the two alternative approaches to the digital world: namely, decentralised architectures and the commons (Bauwens 2005a; Bauwens, Kostakis and Pazaitis 2019).

\section{3. (De-)centralisation and Power: An Interdisciplinary Issue}

Far from being a relatively recent development that only began with Napster, P2P is one of the oldest architectures in the world of telecommunications (Oram 2001); Usenet $^{2}$ (Paloque-Bergès 2017), with its newsgroups, and ARPANET ${ }^{3}$ (Abbate 2000), the

${ }^{2}$ https://en.wikipedia.org/wiki/Usenet

${ }^{3}$ https://en.wikipedia.org/wiki/ARPANET 
precursor of the Internet, can be classified as P2P networks. Some authors have successfully argued that $\mathrm{P} 2 \mathrm{P}$ tools targeting the general public, emerging around the year 2000 with the sharing of music and video files, would have brought the Internet back to its origins, when every computer had equal rights in the network (Minar and Hedlund 2001). Lower costs on the one hand, and the increasing availability of computing capacity, bandwidth and storage on the other, paralleled by the growth of the Internet, have created new fields of application for P2P networks. Over the years, this has led to an increase in the variety and number of $\mathrm{P} 2 \mathrm{P}$ applications, and to an increase in controversies concerning the limits and performance, as well as the economic, social, cultural and legal implications, of these applications. ${ }^{4}$

Similarly, while the development of peer production and governance models of the digital commons has been facilitated by the lowering costs of digitisation and networking since 2000, this alternative to the market and the State has been observed for centuries. Commons have been conceptualised by the work of Elinor Ostrom (1990) on the basis of case studies of local communities involved in the management of water, agricultural or fishery resources.

The choice of more or less (de-)centralisation in the technical development of networks, starting with the Internet, and more or less sharing and collaboration in the production and distribution of digital resources and services, touches upon a profoundly political, social, and philosophical issue. How are power, authority and control inscribed into our communication technologies, and how, at the same time, do these technologies re-shape power, authority and control? How can economic, creative and governance models other than capitalism be sustainable? This question has been examined by multiple disciplines, such as the sociology of science and technology, information and communication sciences, economics, political economy, law and network engineering. It touches on current issues such as the growing place occupied by the GAFAM Internet giants, the debates on surveillance and privacy within networks, marked in 2013 by Edward Snowden's revelations, the production of work and value outside of traditional labour and the debate over universal income.

In light of another consequence of the excesses of capitalism - the Uberisation of the sharing economy - the definition of alternative platform models such as platform cooperativism (Scholz 2017) emerges. The sharing economy is a misnamed concept as it does not bear any similarities with the sharing of computing resources in P2P architectures and the sharing of working arrangements and products as commons, besides the fact that a resource appears to be 'shared'. A more appropriate term would be 'short-term rental' (as with AirBnB) or 'short-term provision of services' (as with Uber), describing the integration of sources that were previously outside the market (e.g., a spare room) into the market, or the lowering of the transaction costs of commercial service providers (e.g., taxi drivers)(Schöpf 2015).

Today, an Internet architecture based on mandatory passage points, centralisation and hierarchisation is dominant but nevertheless questioned for its excesses of supervision, surveillance and hegemony (Tréguer 2019). Capitalism supported by strict intellectual property regimes can also hinder the sharing of knowledge and access to innovation in society. Unregulated capitalism is being questioned even by liberal politicians at a time of climate change crisis, when $\mathrm{Al}$, with the centralised control of personal data, is dominated by US players at the expense of digital sovereignty: French

\footnotetext{
${ }^{4}$ See the work undertaken by the ADAM project (Architectures distribuées et applications multimédias, funded by the French National Agency for Research from 2010 to 2014: adam.hypotheses.org).
} 
President Macron called in March 2018 for a third way to US and Chinese approaches in order to "create an alternative model for data production and governance that is based on the public interest". ${ }^{5}$

\section{4. 'Reclaiming' Digital Services and Data?}

In times such as these, as the world struggles with the Covid-19 pandemic and related economic and social upheavals, there seems to be momentum for action to take place. The production of a vaccine requires data to be shared and patents to be pooled as a common (on microbial research commons, see Reichman, Uhlir and Dedeurwaerdere 2016). As re-emphasised by recent Covid-19-related proposals ${ }^{6}$, biomedical knowledge and medicine patents would be beneficial for public health, the main challenge being to define common-pool models able to accommodate both public and commercial interests. This challenge requires actors to gather all necessary tests, data, knowledge, technology and biological material covered by different areas of intellectual property protecting the pharmaceutical shareholders' monopoly and incentive to invest. And such pool members, despite diverging interests, should define governance rules allowing both access and innovation, similarly to the way that the human genome ${ }^{7}$ had already been produced collaboratively and shared online.

In this context, the P2P option acquires novel meaning. What role can the decentralisation of technical network architectures play in this historical moment, when invasions of privacy and surveillance capitalism practices are very often pervasive and embedded in technology (Masutti 2020)? Are distributed and decentralised network architectures, as Philippe Aigrain (2010) has suggested, opportunities for the re-appropriation of Internet services - tools of governance likely to return to the original organisation of cyberspace ${ }^{8}$ ?

In the context of smart cities and algorithmic governance, citizen data could either be managed as a commons, or handed over to private companies developing applications and controlled by centralised "control points" (DeNardis 2014). Such a dynamic raises similar questions of control and opportunities for citizen re-appropriation and governance as data commons, without exclusive intellectual property. Data citizens produce when using municipal digital services can be governed democratically, as urban or data commons. Such policies are needed to avoid smart cities to turn into dystopian 'safe cities' based on surveillance capitalism. Open data on public transportation designed as commons (Teli et al. 2015), P2P energy production within decentralised networks (Giotitsas, Pazaitis and Kostakis 2015), data generated by applications such as participatory-science Internet of Things captors to measure street pollution rates, or Internet of Bodies-based smart devices to monitor our health signs (Matwyshyn 2019): all of these projects generate big data. If kept open, massively clustered and mined, such data can be useful for policy decision and scientific research; however, the data

${ }^{5}$ https://latest.13d.com/emmanuel-macron-ai-political-revolution-dystopian-ai-france-gdpr4e60d4090c54

${ }^{6}$ https://www.commonsnetwork.org/news/costa-rica-is-right-we-need-a-global-coronavirusknowledge-pool/ https://www.commonsnetwork.org/uncategorized/corona-private-medicine-vs-public-health/ https://www.commonsnetwork.org/news/the-medicines-patent-pool-a-remedy-for-the-anticommons/

${ }^{7}$ https://www.genome.gov/human-genome-project/What

8 The same author had already worked on the sharing of culture through these same P2P networks and proposed economic models for financing culture (Aigrain 2012). 
includes sensitive personal information, such as individual location or health status, which should be protected as such.

Privacy and commons may intuitively seem at odds, but proposals to apply the analytical framework of knowledge commons to private data, seen as contextualised personal information flow, have been made (Sanfilippo, Frischmann and Standburg 2018). Aufrère and Maurel (2018) propose the linking of privacy to labour law negotiation mechanisms and social protection, in order to develop a legal framework to protect social rights on data we generate as digital labour collective rights and to exploit them as a commons. The conceptualisation of theoretical alternatives to govern algorithmic decision-making systems and the data these systems currently collect and process within closed boxes is urgently needed. Springing from such collective, inclusive, participatory models, legal and licensing framework could be developed to accompany the urban and Al data flow, governed as a privacy-friendly commons flowing through P2P infrastructure based on post-capitalist, non-proprietary values of sharing, rather than controlled by centralised organisations.

\section{The Way Forward: Challenges and Opportunities}

Several factors complicate, or slow down, the widespread adoption of P2P technologies and commons-based models. These technologies and models are fragile, sometimes threatened by complex, unsustainable technical architecture, unsuitable legal frameworks, pollution, appropriation, or the disappearance of contributing peers. Indeed, decentralised organisational forms suffer from technical and governance complications inherent to systems where it is difficult to assign clear responsibility for actions, and also to monitor possible violations. This can make them more fragile in the face of the law, requiring communities to spend energy not only in producing and maintaining them, but also to ensure that they will not eventually be considered as illegal. A legal and political defence of the commons (Tréguer and Dulong de Rosnay 2020) is necessary to ensure that P2P file sharing remains authorised.

Another difficulty for P2P and the commons is to establish 'easy' and sustainable business models, making the former more fragile in the face of a digital market that tends towards near-monopoly by taking advantage of 'snowballing' effects and massive data mining. However, in a digital world that rapidly evolves and reconfigures itself, $\mathrm{P} 2 \mathrm{P}$ remains an interesting alternative to respond to certain risks introduced by the centralisation of the Internet.

At the crossroads of decentralised architectures and digital or infrastructure commons are Internet community networks (CNs), developed and maintained by collectives of citizens as an alternative to commercial access providers, and based on values of personal data protection and freedoms. The willingness to 'technically' counter breakdowns, disruptions, surveillance, intrusions into privacy, content dispossession, exclusive appropriation and extraction of knowledge, exclusion on the basis of data mining, or to compensate for the lack of connection in isolated areas - all of these are practical and political reasons behind many alternative Internet projects based on P2P to create and maintain community networks (see the work of the netCommons project ${ }^{9}$, 2016-2018, as well as Dulong de Rosnay and Tréguer 2019). The direct transmission of data between machines in a decentralised network can promote more efficient content exchange (Hales 2006), greater freedom and possibly the emergence of new organisational, social and legal principles. P2P systems can also provide innovative solutions to protect personal liberties and counter surveillance, or foster the emergence

${ }^{9}$ https://netcommons.eu/ 
of alternative decision-making processes and participatory environments (Elkin-Koren and Salzberger 2004): this is made possible by the direct exchange of content, especially when combined with encryption (see the work of the Nextleap project ${ }^{10}, 2016$ 2018). The implications of the choice of decentralisation go beyond technical performance to redefine concepts such as security and confidentiality, and to reconfigure the locations of data and exchanges and the boundaries between user and network.

\section{Conclusions}

At a practical level, a wide range of models combining different social, political, technical and economic arrangements exist for platforms at the crossroads of decentralisation, commons and peer production. Thus, we have sought in a previous research article for the tripleC journal (Dulong de Rosnay and Musiani 2016) to systematise these models in a typology that includes features such as the ownership of means of production, technical architecture and design, social organisation and governance of work patterns, ownership of the peer-produced resource, and value of the output. Working on this typology has usefully reminded us that there is no 'ideal' mix of levels of decentralisation that constitutes a valid or successful alternative; however, it is appropriate to elaborate a comprehensive frame of reference for researchers and practitioners to "delve into which parameters may facilitate or impede dynamics tending towards profit and exclusion or, on the contrary, collective governance of commonsbased peer production and redistribution of value" $(2016,203)$.

For these alternatives to digital capitalism to have a chance, at least three things are needed: a legal, political, economic and social environment that preserves the possibility of ethical and responsible innovation and a culture of sharing; a favourable context for research on these themes, where researchers can operate in a multi- and interdisciplinary approach with a variety of actors in 'civil society' including developers, other technologists, projects, policy-makers, public authorities and cooperatives; and finally, a detailed knowledge of the functioning of information systems and the history of technology and infrastructure, in order to influence the present and enable alternatives to emerge with sustainability for the future.

\section{References}

Abbate, Janet. 2000. Inventing the Internet. Cambridge, MA: The MIT Press.

Aigrain, Philippe. 2012. Sharing: Culture and the Economy in the Internet Age. Amsterdam: Amsterdam University Press. Accessed August 13, 2020. https://library.oapen.org/handle/20.500.12657/34556

Aigrain, Philippe. 2010. Declouding Freedom: Reclaiming Servers, Services and Data, in 2020 FLOSS Roadmap (3rd Edition). Formerly available at https://flossroadmap.coment.com/text/NUFVxf6wwK2/view/

Aufrère, Laura and Lionel Maurel. 2018. Pour une protection sociale des données personnelles. Working Paper Projet EnCommuns. Accessed August 13, 2020. https://hal.archives-ouvertes.fr/hal-01903526

Bauwens, Michel. 2005a. P2P and Human Evolution: Placing Peer to Peer Theory in an Integral Framework. Integral World: Exploring Theories of Everything [website]. Accessed August 13, 2020. http://www.integralworld.net/bauwens2.html

Bauwens, Michel. 2005b. The Political Economy of Peer Production. CTheory. Accessed August 13, 2020. http://www.ctheory.net/articles.aspx?id=499

Bauwens, Michel, Vasilis Kostakis, and Alex Pazaitis. 2019. Peer to Peer: The Commons Manifesto. London: University of Westminster Press. https://doi.org/10.16997/book33

\footnotetext{
${ }^{10}$ http://nextleap.eul
} 
Benkler, Yochai. 2006. The Wealth of Networks: How Social Production Transforms Markets and Freedom. New Haven: Yale University Press.

Bollier, David and Robert Pavlovich. 2008. Viral Spiral: How the Commoners Built a Digital Republic of Their Own. New York: New Press.

DeNardis, Laura. 2014. The Global War for Internet Governance. New Haven: Yale University Press.

Dulong de Rosnay, Mélanie and Félix Tréguer, eds. 2019. Telecommunications Reclaimed: a Hands-on Guide to Networking Communities. Internet Society/Association for Progressive communications. Accessed August 13, 2020. https://www.netcommons.eu/?q=telecommunications-reclaimed

Dulong de Rosnay, Mélanie and Hervé Le Crosnier. 2012. An Introduction to the Digital Commons: From Common-Pool Resources to Community Governance. Building Institutions for Sustainable Scientific, Cultural and Genetic Resources Commons [conference papers]. Louvain-la-Neuve: International Association for the Study of the Commons. Accessed August 13, 2020. https://halshs.archives-ouvertes.fr/halshs-00736920

Dulong de Rosnay, Mélanie and Francesca Musiani. 2016. Toward a (De-)CentralizationBased Typology of Peer Production. tripleC: Communication, Capitalism \& Critique 14 (1), 189-207.

Elkin-Koren, Niva and Eli M. Salzberger. 2004. Law, Economics and Cyberspace. Cheltenham: Edward Elgar Publishing.

Fuchs, Christian. 2020. The Ethics of the Digital Commons. Journal of Media Ethics 35 (2): 112-126. https://doi.org/10.1080/23736992.2020.1736077

Giotitsas, Chris, Alex Pazaitis, and Vasilis Kostakis. 2015. A peer-to-peer approach to energy production. Technology in Society 42: 28-38. https://doi.org/10.1016/j.techsoc.2015.02.002

Hales, David. 2006. Emergent Group-Level Selection in a Peer-to-Peer Network. Complexus 3: 108-118.

Ku, Raymond Shih Ray. 2002. The Creative Destruction of Copyright: Napster and the New Economics of Digital Technology. University of Chicago Law Review 69: 263-324.

Linkov, Igor, Benjamin D. Trump, Kelsey Poinsatte-Jones, and Marie-Valentine Florin. 2018. Governance Strategies for a Sustainable Digital World. Sustainability 10 (2): 440.

Masutti, Christophe. 2020. Affaires privées: Aux sources du capitalisme de surveillance. Caen : C\&F Editions.

Matwyshyn, Andrea. 2019. The Internet of Bodies. William \& Mary Law Review 61 (1):77167. Accessed August 13, 2020. https://ssrn.com/abstract=3452891

Méadel, Cécile and Francesca Musiani, eds. 2015. Abécédaire des architectures distribuées. Paris: Presses des Mines.

Minar, Nelson and Mark Hedlund. 2001. A Network of Peers - Peer-to-Peer Models through the History of the Internet. In Peer-to-Peer: Harnessing the Power of Disruptive Technologies, edited by Andy Oram, 9-20. Sebastopol, CA: O'Reilly.

Musiani, Francesca. 2015. Giants, Dwarfs and Decentralized Alternatives to Internet-based Services: An Issue of Internet Governance. Westminster Papers in Communication and Culture 10 (1): 81-94. http://doi.org/10.16997/wpcc.214

O'Neil, Mathieu. 2009. Cyberchiefs: Autonomy and Authority in Online Tribes. London: Pluto Press.

Oram, Andy, ed. 2001. Peer-to-Peer: Harnessing the Power of Disruptive Technologies. Sebastopol, CA: O'Reilly.

Ostrom, Elinor. 1990. Governing the Commons: The Evolution of Institutions for Collective Action. Cambridge: Cambridge University Press.

Paloque-Bergès, Camille. 2017. Usenet as a Web Archive: Multi-layered Archives of Computer-Mediated-Communication. In Web 25: Histories from the first 25 Years of the World Wide Web, edited by Niels Brügger, 227-250. London: Peter Lang Publishing. 
Reichman, Jerome, Paul Uhlir, and Tom Dedeurwaerdere. 2015. Governing Digitally Integrated Genetic Resources, Data, and Literature: Global Intellectual Property Strategies for a Redesigned Microbial Research Commons. Cambridge: Cambridge University Press.

Sanfilippo, Madelyn, Brett Frischmann, and Katherine Standburg. 2018. Privacy as Commons: Case Evaluation Through the Governing Knowledge Commons Framework. Journal of Information Policy 8: 116. https://doi.org/10.5325/iinfopoli.8.2018.0116

Schoder, Detlef and Kai Fischbach. 2003. Peer-to-Peer Prospects. Communications of the ACM 46 (2): 27-29.

Schollmeier, Rüdiger. 2001. A Definition of Peer-to-Peer Networking for the Classification of Peer-to-Peer architectures and applications. Proceedings of the First International Conference on Peer-to-Peer Computing, 27-29.

Scholz, Trebor. 2017. Platform Cooperativism vs. the Sharing Economy. In Big Data \& Civic Engagement edited by Nicolas Douay and Annie Wan, 47-54. Milan: Planum. Accessed August 3, 2020. https://www.researchgate.net/publication/321777389 Big Data Civic Engagement

Scholz, Trebor and Nathan Schneider, eds. 2016. Ours to Hack and to Own: The Rise of Platform Cooperativism, a New Vision for the Future of Work and a Fairer Internet. OR Books.

Schöpf, Simon. 2015. The Commodification of the Couch: A Dialectical Analysis of Hospitality Exchange Platforms. tripleC: Communication, Capitalism \& Critique 13 (1): 11-34. https://doi.org/10.31269/triplec.v13i1.480

Stalder, Felix. 2010. Digital Commons. In The Human Economy: A Citizen's Guide, edited by Keith Hart, Jean-Louis Laville and Antonio David Cattani, 313-324. Cambridge: Polity Press.

Teli, Maurizio, Silvia Bordin, María Menéndez Blanco, Giusi Orabona, and Antonella De Angeli. 2015. Public Design of Digital Commons in Urban Places: A Case Study. International Journal of Human-Computer Studies 81: 17-30. http://dx.doi.org/10.1016/j.ijhcs.2015.02.003

Tréguer, Félix. 2019. L'utopie déchue. Une contre-histoire d'Internet, XV-XXI siècles. Paris: Fayard.

Tréguer, Félix and Mélanie Dulong de Rosnay. 2020. The Political Defence of the Commons: The Case of Community Networks. tripleC: Communication, Capitalism \& Critique 18 (2): 560-574. https://doi.org/10.31269/triplec.v18i2.1108

\section{About the Authors}

\section{Mélanie Dulong de Rosnay}

Mélanie Dulong de Rosnay has been associate research professor at the French National Centre for Scientific Research (CNRS) since 2010 and is director of the CNRS Center for Internet and Society (CIS CNRS), which she co-founded in 2019.

\section{Francesca Musiani}

Francesca Musiani has been associate research professor at the French National Centre for Scientific Research (CNRS) since 2014 and is deputy director of the CNRS Center for Internet and Society (CIS CNRS), which she co-founded in 2019. 